\title{
Correction to: A review on nanomaterial-modified optical fiber sensors for gases, vapors and ions
}

\author{
Dnyandeo Pawar $^{1}$ (1) - Sangeeta N. Kale ${ }^{2}$
}

Published online: 23 April 2019

(C) Springer-Verlag GmbH Austria, part of Springer Nature 2019

\section{Correction to: Microchimica Acta \\ https://doi.org/10.1007/s00604-019-3351-7}

The published version of this article, unfortunately, contains error. Corrections in Figs. 1, 3 and 5 were incorrectly carried out. Given in this article are the correct figures.

The online version of the original article can be found at https://doi.org/ 10.1007/s00604-019-3351-7

Dnyandeo Pawar

pawar.dnyandeo@gmail.com

1 Advanced Materials and Sensors Division (V4), CSIR-Central Scientific Instruments Organisation, Chandigarh 160030, India

2 Department of Applied Physics, Defence Institute of Advanced Technology, Girinagar, Pune 411025, India 


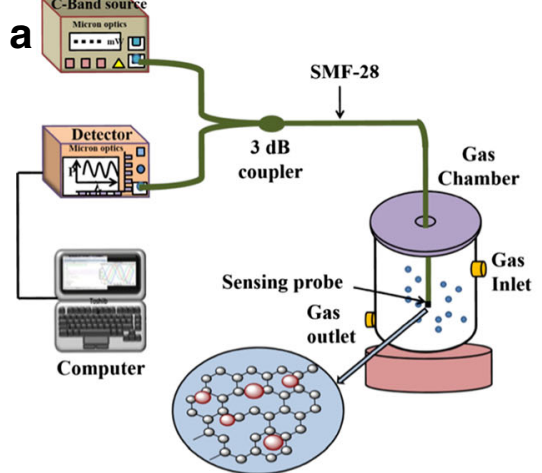

a

C

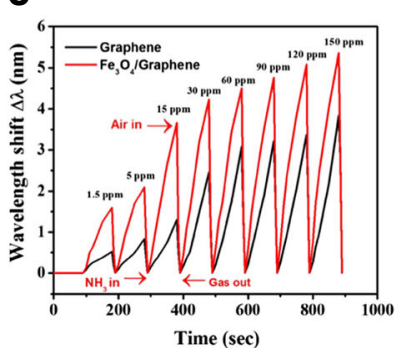

b

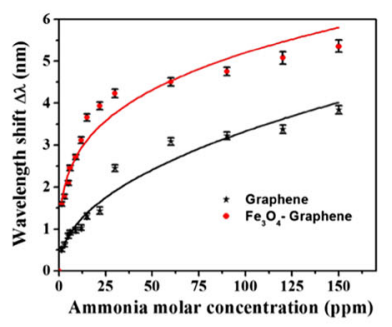

e

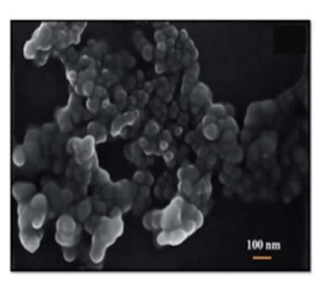

f

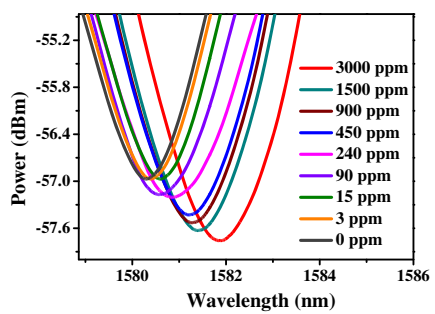

d

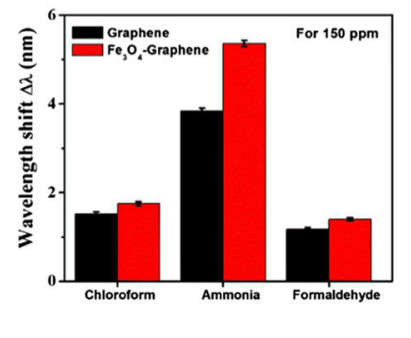

g

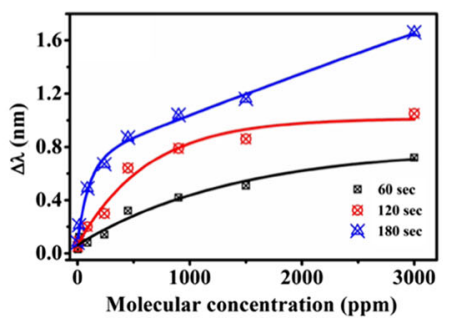

h

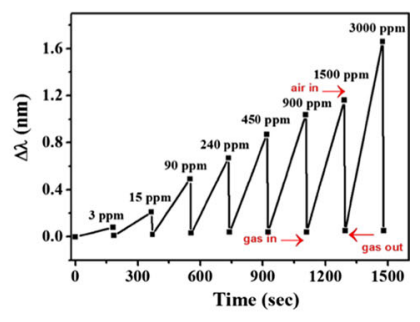

Fig. 1 a Experimental set up of an $\mathrm{Fe}_{3} \mathrm{O}_{4}$ graphene FPI for $\mathrm{NH}_{3}$ sensing (sensing material is coated at the end of the fiber tip). $\mathbf{b}$ Dip wavelength shift of graphene coated FPI and $\mathrm{Fe}_{3} \mathrm{O}_{4}$-graphene coated FPI with $\mathrm{NH}_{3}$ concentration ranging from $1.5-150 \mathrm{ppm}$. c. Time response curve of graphene coated FPI and $\mathrm{Fe}_{3} \mathrm{O}_{4}$-graphene coated FPI with $\mathrm{NH}_{3}$ concentration from $1.5-150 \mathrm{ppm}$. d Cross-sensitivity study of graphene coated FPI and $\mathrm{Fe}_{3} \mathrm{O}_{4}$ graphene coated FPI at 150 ppm $\mathrm{NH}_{3}$ gas. e FESEM

image of nano-carbon. $\mathbf{f}$ Spectral response of nano-carbon coated FPI with $\mathrm{NH}_{3}$ sensing concentration ranging from 3-3000 ppm. g Response function characteristics of nano-carbon FPI in terms of wavelength shift with $\mathrm{NH}_{3}$ concentration from $3-3000 \mathrm{ppm}$ at $60 \mathrm{secs}, 120 \mathrm{secs}$, and $180 \mathrm{secs}$ respectively. $\mathbf{h}$ Time response curve of nanocarbon FPI at different ppm levels for nano-carbon. Reprinted with permission from [103, 116]. Copyright of Royal Society of Chemistry 


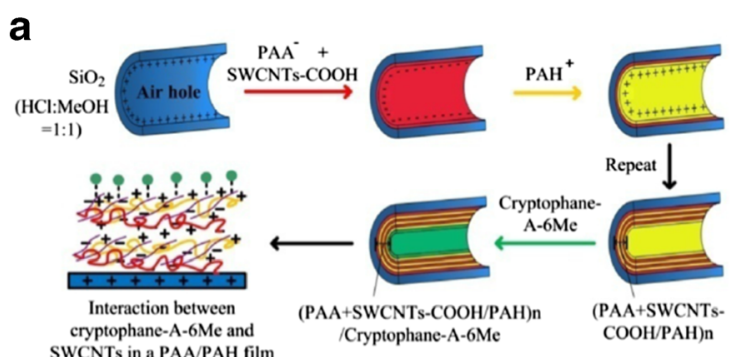

C

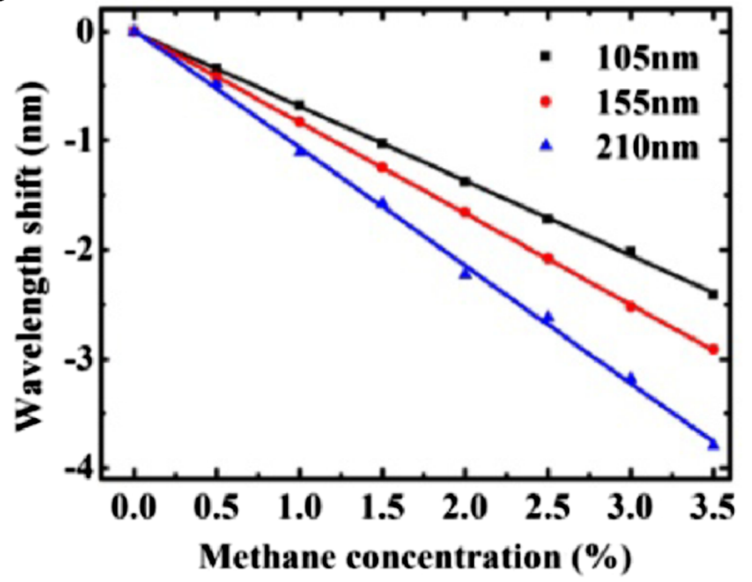

Fig. 3 a Coating process of PAA-CNTs/PAH nanofilms and cryptophane -A-6Me layer on to the inner surface of PCF cladding air holes. b Simulation model of PCF-LPG with sensing film coated on to the cladding air holes and its cladding mode $\mathrm{LP}_{11}$ in plane $\mathrm{A}$ and plane $\mathrm{E}$. $\mathbf{c}$

b

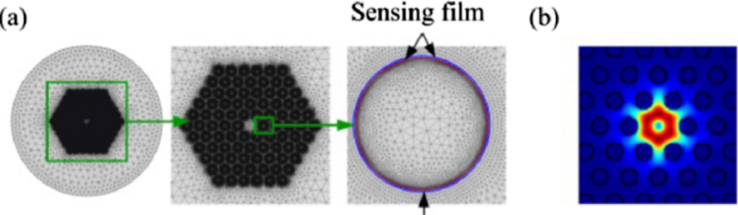

Plane A

Air holes

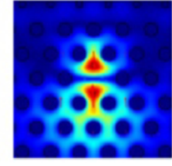

Plane E Internal surface

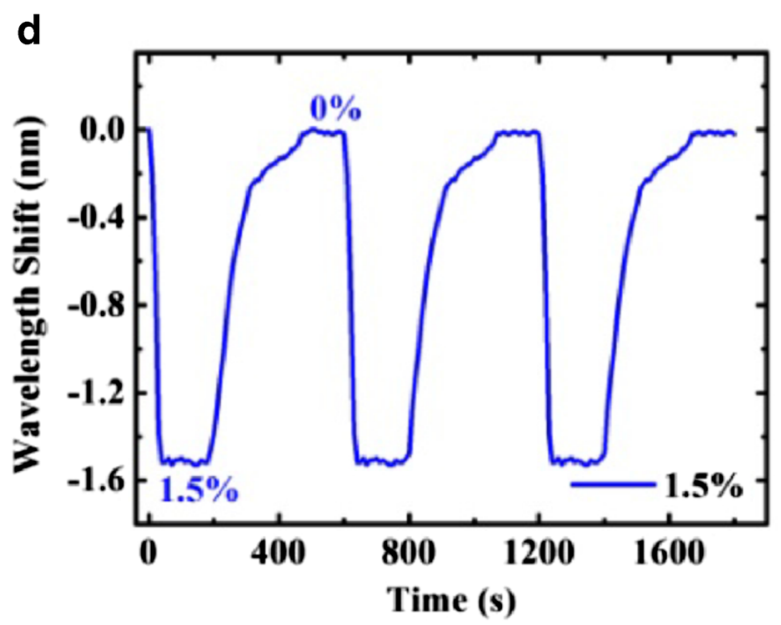

Dip wavelength shift with respect to change in $\mathrm{CH}_{4}$ concentration from 0\%-3.5\%. d Sensor time response graph for $210 \mathrm{~nm}$ thickness film for exposure of $1.5 \% \mathrm{CH}_{4}$ concentration. Reprint with permission from Ref. [176]. Copyright of The Optical Society 
a
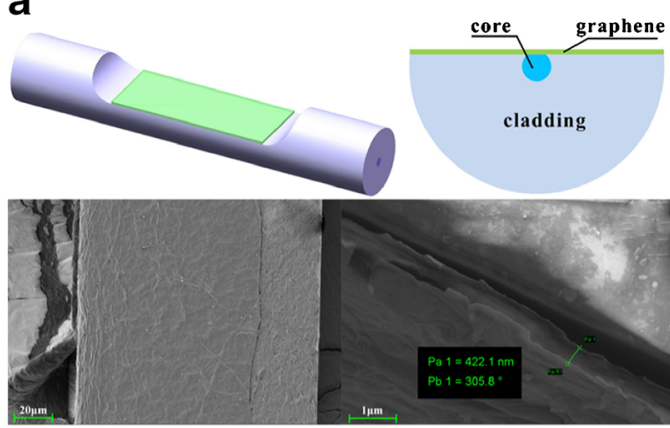

d
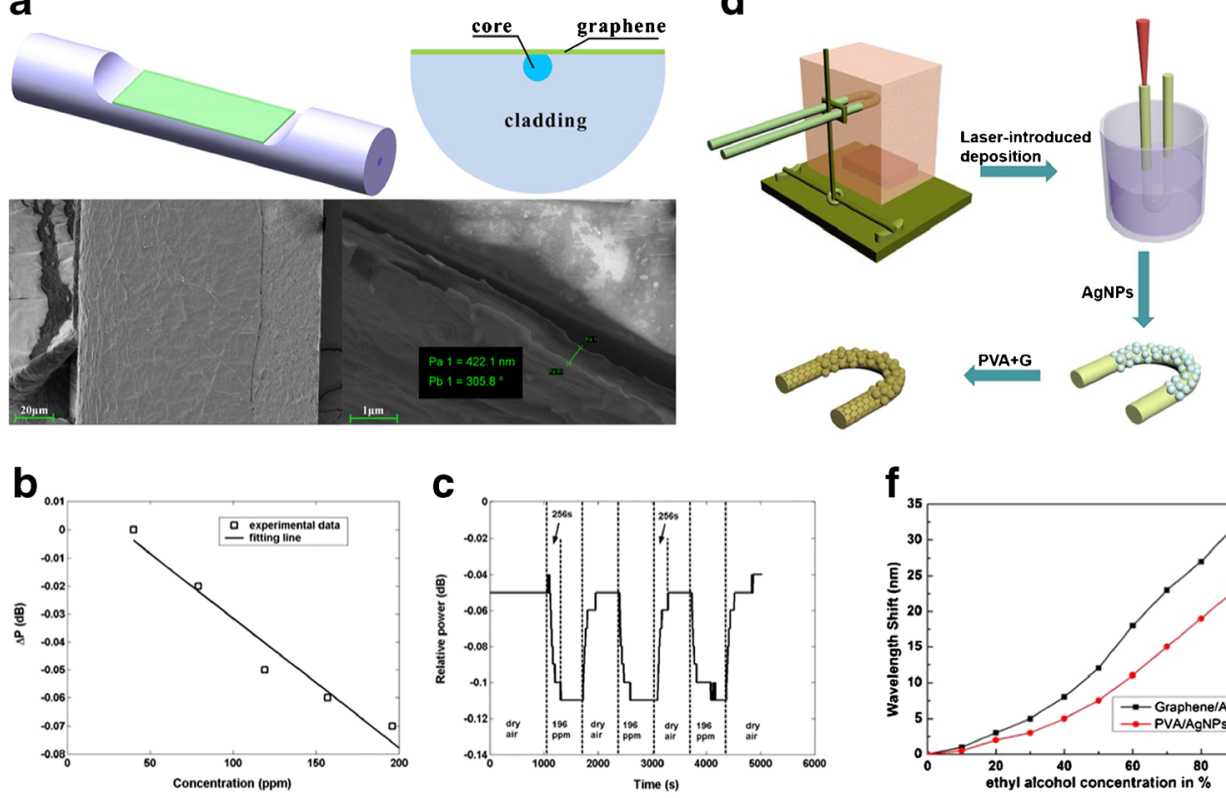

C

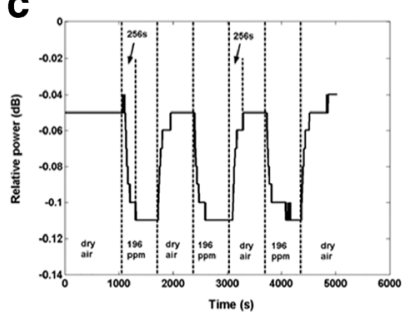

Fig. 5 a Sketch of rGO coated side polished optical fiber sensing probe with its cross section and its SEM images. $\mathbf{b}$ Optical power variation of rGO coated side polished optical fiber sensor with varied toluene concentration from 40 to $196 \mathrm{ppm}$. c Optical power variation of rGO coated side polished optical fiber sensor as a function of time with toluene concentration of $196 \mathrm{ppm}$. d Schematic diagram of the process for the fabrication of the U-bent SPR sensor. e Response of SPR spectrum

The original article has been corrected.

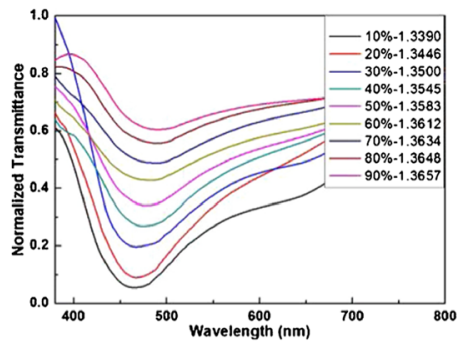

g
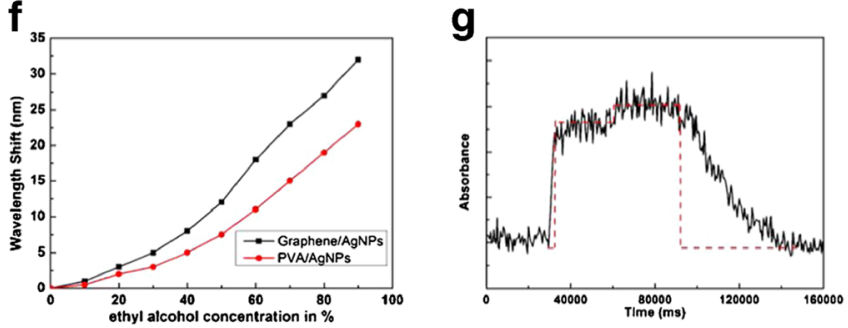

of coated graphene/AgNPs U-bent sensor with different concentrations of aqueous ethanol. f Shift of the SPR sensor coated with graphene/AgNPs and PVA/AgNPs with different concentrations of aqueous ethanol. $g$ Time response curve of graphene/AgNPs SPR sensor for aqueous ethanol concentration of $50 \%$. Reprinted with permission from Ref. [85, 190]. Copyright of The Optical Society and Elsevier

Publisher's note Springer Nature remains neutral with regard to jurisdictional claims in published maps and institutional affiliations. 